\title{
Computational Modelling Strategies for Nonlinear Response Prediction of Corroded Circular RC Bridge Piers
}

\author{
Mohammad M. Kashani, ${ }^{1}$ Laura N. Lowes, ${ }^{2}$ Adam J. Crewe, ${ }^{1}$ and Nicholas A. Alexander ${ }^{1}$ \\ ${ }^{1}$ Department of Civil Engineering, University of Bristol, Bristol BS8 1TR, UK \\ ${ }^{2}$ Department of Civil and Environmental Engineering, University of Washington, Seattle, WA 98195-2700, USA \\ Correspondence should be addressed to Mohammad M. Kashani; mehdi.kashani@bristol.ac.uk
}

Received 30 December 2015; Accepted 19 April 2016

Academic Editor: Seung-Jun Kwon

Copyright (c) 2016 Mohammad M. Kashani et al. This is an open access article distributed under the Creative Commons Attribution License, which permits unrestricted use, distribution, and reproduction in any medium, provided the original work is properly cited.

\begin{abstract}
A numerical model is presented that enables simulation of the nonlinear flexural response of corroded reinforced concrete (RC) components. The model employs a force-based nonlinear fibre beam-column element. A new phenomenological uniaxial material model for corroded reinforcing steel is used. This model accounts for the impact of corrosion on buckling strength, postbuckling behaviour, and low-cycle fatigue degradation of vertical reinforcement under cyclic loading. The basic material model is validated through comparison of simulated and observed responses for uncorroded RC columns. The model is used to explore the impact of corrosion on the inelastic response of corroded RC columns.
\end{abstract}

\section{Introduction}

A significant number of older major infrastructure artefacts, located in an aggressive environment, suffer from material aging and deterioration $[1,2]$. In order to provide a durable and reliable solution, the functionality, safety, and service life of various infrastructure artefacts should be estimated using the best available engineering science. Therefore, for existing deteriorated infrastructure, a rational maintenance plan should be employed in accordance with their current condition. Recently, limited funding has implied the need for a new bridge management system that can capture all these complexities within a single comprehensive framework so that the maintenance strategy of bridge networks can be optimised.

Among different deterioration mechanisms the corrosion of reinforcing bars in RC structures is the most common type of deterioration mechanisms $[1,2]$. Moreover, a huge number of these corroded structures are also in high seismicity regions. This has led researchers around the world to investigate the influence of reinforcement corrosion on the seismic performance of existing RC structures [3-11]. Other researchers have studied the impact of reinforcement corrosion on cyclic behaviour of corroded RC beams and columns experimentally [12-14]. The experimental results showed that corrosion will affect the failure mechanisms of flexural RC components. In several cases, premature buckling of longitudinal reinforcement has been observed. This is due to the combined effect of nonuniform pitting corrosion along the length of longitudinal reinforcement and corrosion of horizontal tie reinforcement. Once corroded bars buckled under cyclic loading, they fracture at lower drift demands due to low-cycle high amplitude fatigue degradation. These observations from the experimental studies suggest that the combined effect of inelastic buckling and nonuniform pitting corrosion results in a significant reduction in low-cycle fatigue life of corroded RC elements.

Furthermore, several researchers investigated the effect of corrosion on stress-strain behaviour of reinforcing bars in tension [15-20]. References [21-25] included a comprehensive experimental and computational study on the inelastic behaviour of isolated corroded reinforcing bars, including the impact of corrosion on inelastic buckling and degradation due to low-cycle fatigue. These results are in good agreement with the results observed by other researchers who studied the cyclic behaviour of RC components.

Moreover, in recent years, several researchers have studied the seismic vulnerability and fragility analysis of corroded RC bridges [3-11]. They have investigated the effect of 
reinforcement corrosion on the nonlinear behaviour and response of RC bridges subject to seismic loading through nonlinear fibre-based finite element analysis [26-28].

However, they have used very simple uniaxial material models to model the impact of corrosion on the stress-strain behaviour of reinforcing steel. In most cases the corrosion damage has only been limited to the reinforcing steel by considering an average reduced area and/or reduced yield strength. Furthermore the impact of corrosion on ductility loss, reduced low-cycle fatigue life and inelastic buckling of vertical reinforcement, and corrosion induced damage to cover and core confined concrete are ignored. In other words, the extent of corrosion damage on RC bridges has been underestimated in previous studies.

Based on the previous research by Kashani et al. [2325 ] it is evident that the impact of corrosion on inelastic buckling, cyclic behaviour, and low-cycle fatigue degradation of reinforcing bars must be included in modelling corroded $\mathrm{RC}$ columns. As a result of earlier research by Kashani et al. [23-25], they developed a new phenomenological model for corroded reinforcing bars [29] and is used in this paper for modelling.

Prior to the development of the material models developed in $[25,29]$, it was impossible to investigate the combined effect of corrosion damage, inelastic buckling, and low-cycle high amplitude fatigue degradation on nonlinear flexural response of corroded RC columns. Therefore, there is a significant paucity of modelling techniques and guidelines in the literature which is addressed in this paper.

The aim of this numerical exploration study provided in this paper is to discover the impact of different corrosion damage models on the nonlinear flexural response of corroded RC columns. This paper provides comprehensive modelling guidelines to model the nonlinear behaviour of corroded RC bridge piers including the cyclic degradation effects up to complete collapse. The results of this study highlight what damage mechanisms are important to be considered in modelling nonlinear behaviour of corroded RC columns. Moreover, the proposed model is able to capture multiple failure modes of corroded RC columns simultaneously.

To this end, there is a need for a more detailed and accurate numerical model to represent the impact of corrosion on

(i) the vertical and horizontal tie reinforcement (including pitting effects, buckling, ductility loss, and reduced low-cycle fatigue life);

(ii) the cracked cover concrete (including reduced capacity) due to corrosion of vertical reinforcement in column;

(iii) the confined concrete (including reduced capacity and ductility) due to corrosion of horizontal tie reinforcement (also known as confinement reinforcement).

In this paper a numerical model is developed that enables simulation of the nonlinear flexural response of RC components with corroded reinforcement. The model employs a force-based nonlinear fibre beam-column element using OpenSees. The uniaxial material model for corroded reinforcing steel that is developed in [29] is used. This model simulates the stress-strain behaviour of reinforcing steel with the effect of inelastic buckling and low-cycle high amplitude fatigue degradation under cyclic loading. The basic buckling model of reinforcing steel is validated through comparison of simulated and observed experimental responses of RC columns with uncorroded reinforcement [25].

The cover concrete strength is adjusted to account for corrosion induced cracking of the cover concrete while the strength and ductility of the core confined concrete are adjusted to account for corrosion induced damage to horizontal tie reinforcement. The model is used to explore the impact of corrosion on the nonlinear response of RC columns under monotonic and cyclic loading.

The analysis results show that the proposed model in this paper is able to simulate multiple failure modes of corroded columns simultaneously. Therefore, it is evident that the outcome of this research has made a significant improvement to the existing numerical models. This model provides an open source computational platform for seismic vulnerability assessment (including fragility analysis) of corroded RC bridges.

\section{The Proposed Nonlinear Fibre Beam-Column Element Model}

The force-based nonlinear fibre beam-column element with Gauss-Lobatto integration scheme (available in OpenSees) is used here (Figure 1(a)). To avoid any localisation effects [30, 31] due to the softening behaviour of vertical reinforcement in the postbuckling region the column is modelled using two force-based elements. The first element has three integration points and the second element has five integration points. The length of the first element is taken to be $6 L_{\text {eff }}$, where $L_{\text {eff }}$ is the calculated buckling length of the vertical reinforcement (Figure 1(a)) which is discussed in Section 4. This allows control of the position of the first integration point which is set equal to the buckling length of the vertical reinforcement that is used to define the material model of the reinforcing bars. It should be noted that the new uniaxial material model developed by [29] is used here to model the stressstrain behaviour of the vertical reinforcing bars. This model accounts for the combined impact of geometrical nonlinearity due to inelastic buckling and material nonlinearity as well as low-cycle high amplitude fatigue degradation and corrosion damage in a single-material model. Further details are available in Sections 5.1 and 5.2.

To model the slippage of the vertical reinforcement at the column-foundation interface, a zero-length section element is used at the base. The detailed discussion and validation of the proposed modelling methodology are available in [25]. Therefore, only the relevant uniaxial material models to be used in the fibre section are discussed here. Figure 1(b) also shows the fibre section assigned to the proposed beamcolumn element. The relevant sections discussing the material models are also noted in Figure 1(b).

The implementation of the corrosion damage models that are developed by $[21-25,29]$ into the OpenSees abstract 


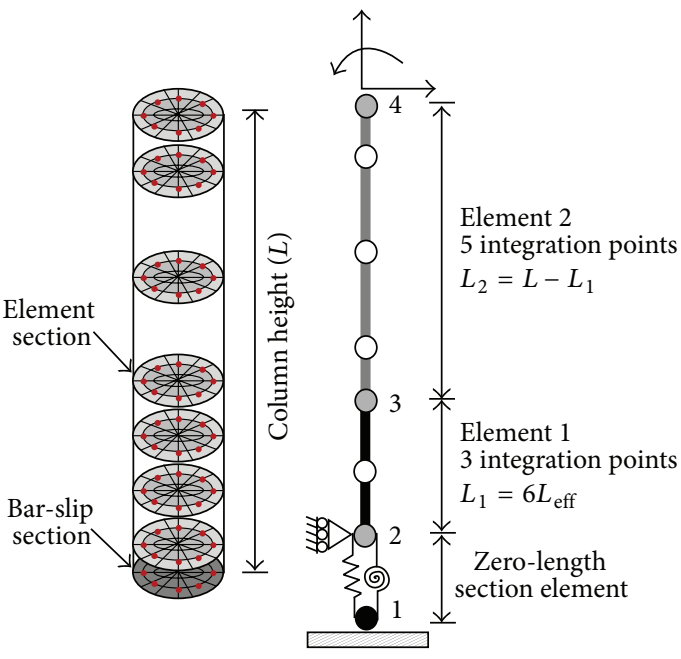

(a)
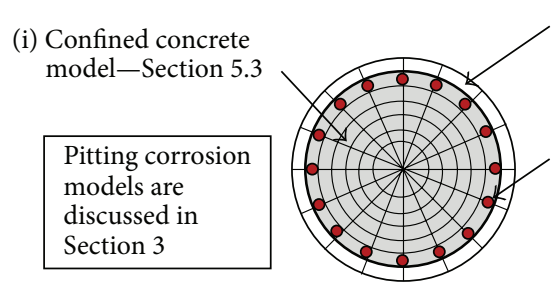

(b) (ii) Unconfined cover concrete modelSection 5.4

(iii) Reinforcing steel model including inelastic buckling and damage models-Sections 5.1 and 5.2

(iv) Buckling length calculation-Section 4

FIgURE 1: Proposed finite element model: (a) force-based nonlinear beam-column arrangement; (b) fibre section.

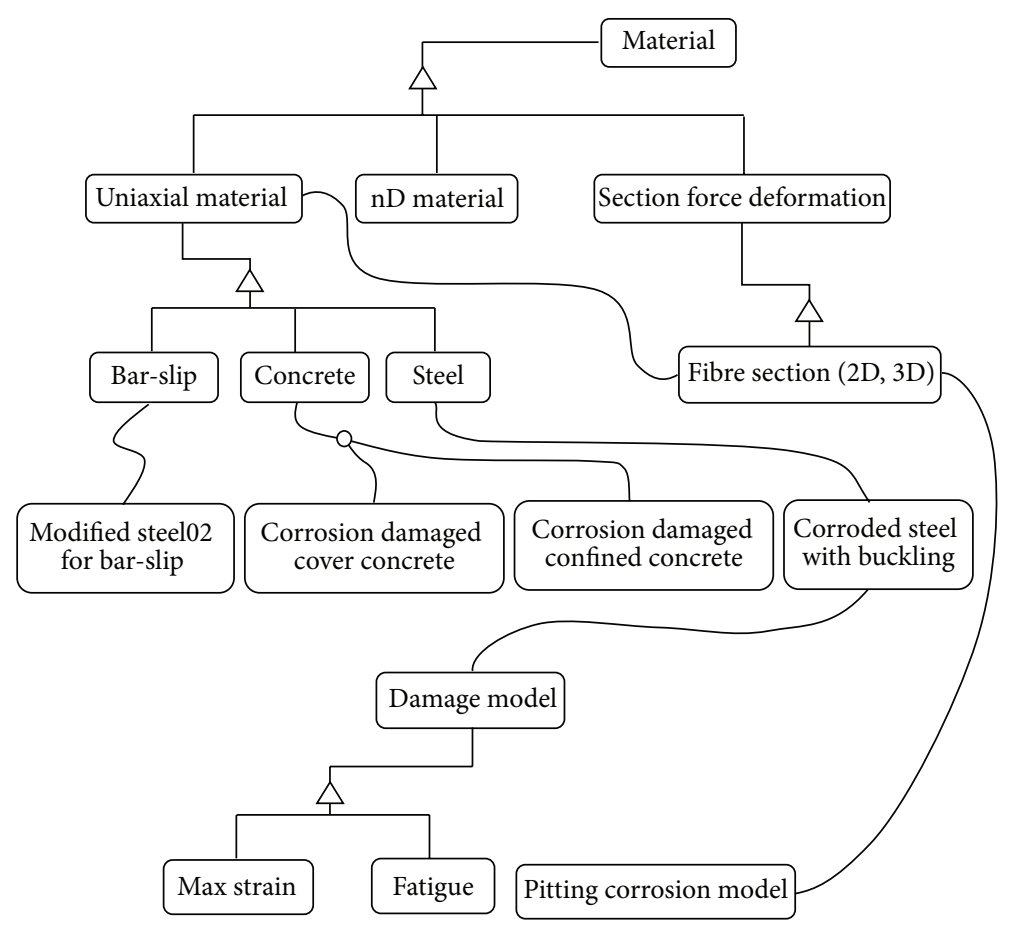

FIGURE 2: Implementation of the corrosion models within the OpenSees abstract classes.

classes is shown in Figure 2. The calculation of buckling length of the corroded vertical reinforcement, uniaxial material models, and corrosion damage models is discussed in Sections 3-5.

\section{Influence of Corrosion on Geometrical Properties of Corroded Bars}

The chloride induced corrosion results in irregular loss of cross section of reinforcing steel known as pitting corrosion.
Several researchers studied the impact of nonuniform corrosion on cross section loss of reinforcing bars [23, 32, 33]. In [23] a 3D optical measurement of corroded bars was conducted to explore the spatial variability of the corrosion pattern. As a result Kashani et al. developed a set of probabilistic distribution models to predict the geometrical properties of corroded bars. They found that the geometrical properties of corroded bars can be modelled using a lognormal distribution. In this study, the mean values of the lognormal distribution models are used to account for the effect of pitting corrosion on the geometrical properties of corroded 


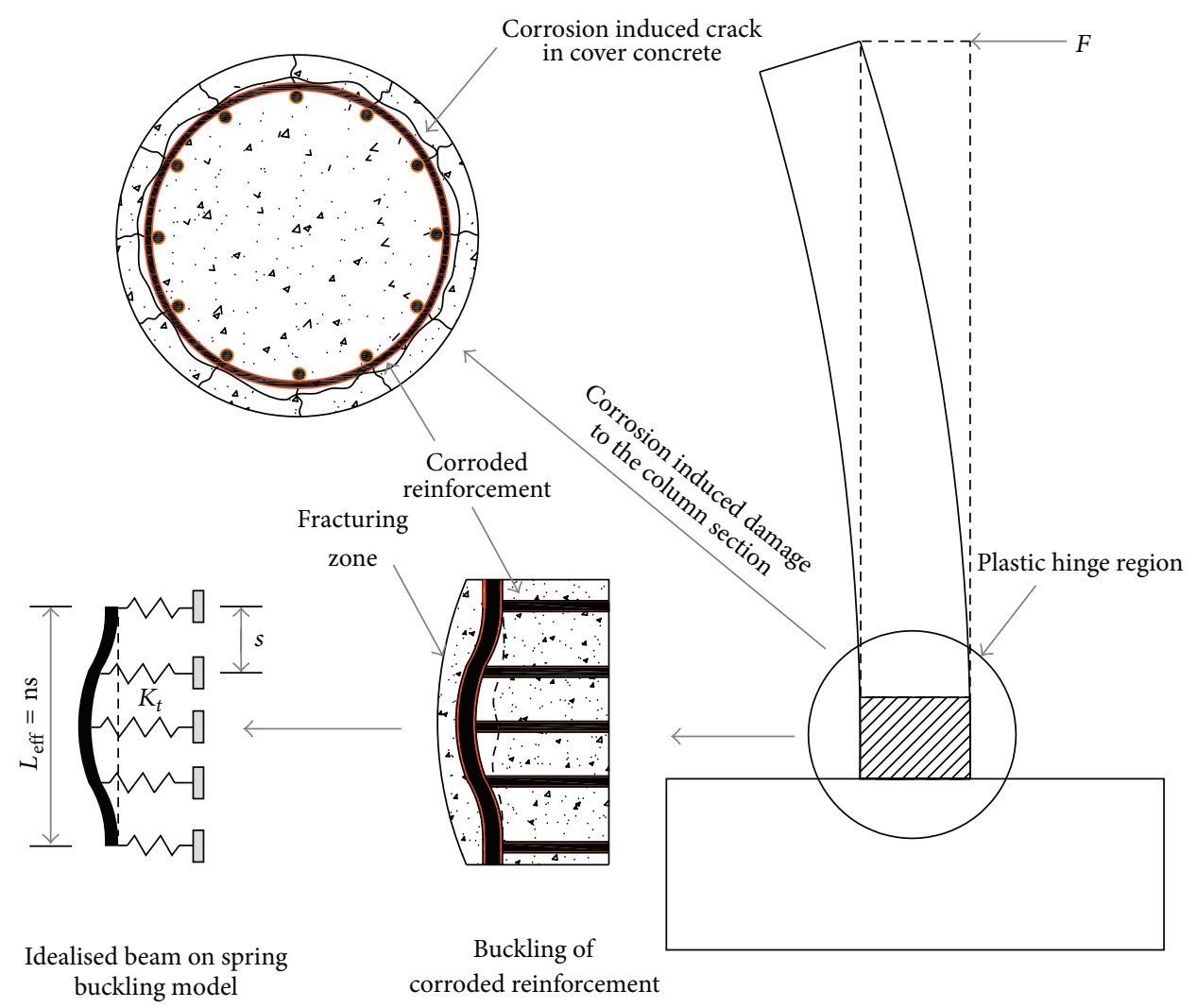

FIgURE 3: Schematic overview of corrosion induced damage to RC column.

bars. In this study the proposed models that developed in [23] are used to model the impact of pitting corrosion on geometrical properties of corroded bars.

\section{Calculation of the Buckling Length considering the Stiffness of Tie Reinforcement}

The detailed discussion and validation of the DhakalMaekawa buckling model are available in $[25,34]$. The same methodology is used here for calculation of the buckling length of corroded vertical reinforcement.

Figure 3 shows a schematic overview of the extent of corrosion damage on a hypothetical RC column. The damage at section level shown in Figure 3 is based on the observed experimental tests by $[35,36]$. The corrosion of vertical reinforcement results in longitudinal cracks at the surface of the column parallel to vertical reinforcement. This will reduce the cross-sectional area and flexural rigidity of the vertical reinforcement which are very important in buckling. Corrosion of horizontal tie reinforcement reduces the volumetric ratio of confinement reinforcement which is very important in providing confinement for core concrete. Furthermore, this will result in splitting the core and cover concrete by creation of horizontal cracks around the perimeter of the column section. Moreover, horizontal ties restrain the vertical bars against buckling and corrosion results in a reduction in stiffness of these ties. Therefore, these parameters need to be considered in calculation of the buckling length.

To account for the effect of corrosion on DhakalMaekawa equations, the flexural rigidity of the vertical reinforcement $(E I)$ and stiffness of horizontal tie reinforcement $\left(K_{t}\right)$ are adjusted. This is discussed in Sections 4.1 and 4.2.

4.1. Influence of Corrosion on Flexural Rigidity of Corroded Bars. The buckling of reinforcing bars is an inelastic buckling phenomenon and, therefore, the elastic flexural rigidity $E_{s} I$ is no longer valid [37]. Reference [34] suggested an average flexural rigidity in which it has been validated against an extensive set of experimental data for uncorroded columns. This has been modified for corroded reinforcement $\left(E I^{\prime}\right)$ and defined as

$$
E I^{\prime}=\frac{E_{s} I_{\min }^{\prime}}{2} \sqrt{\frac{\sigma_{y}^{\prime}}{400}},
$$

where $E_{s}$ and $\sigma_{y}^{\prime}$ are the elastic modulus and yield strength of the corroded vertical reinforcement in $\mathrm{MPa}$, respectively, and $I_{\text {min }}^{\prime}$ is the second moment of area of corroded reinforcement. The detailed calculation of $I_{\min }^{\prime}$ is available in [23].

Corrosion of reinforcing bars affects the second moment of area and yield strength of reinforcement but does not have any influence on the elastic modulus. The yield strength 


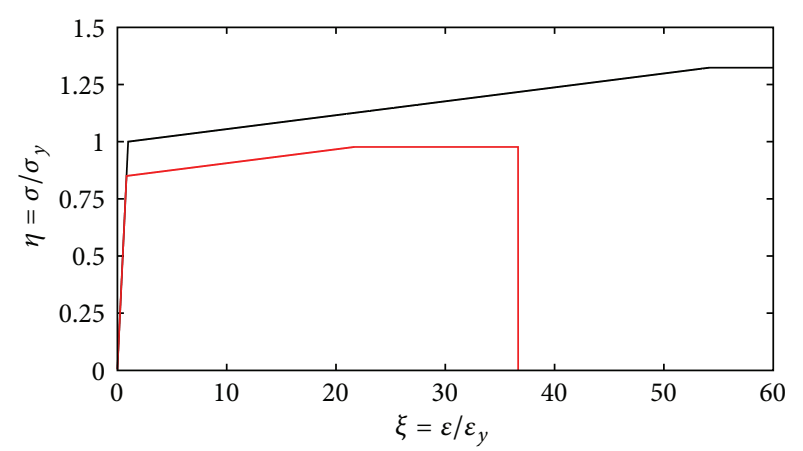

Tension envelope-uncorroded reinforcement
Tension envelope-corroded reinforcement

(a)

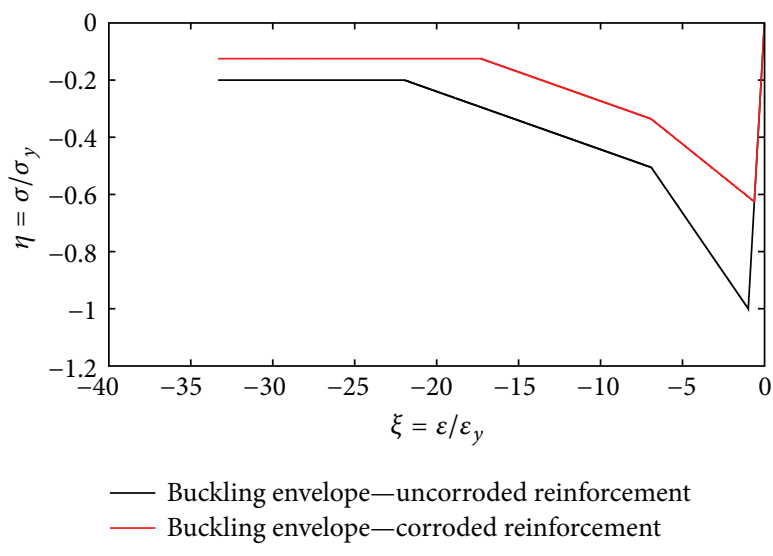

(b)

FIGURE 4: Implemented tension and compression envelopes of corroded bars in OpenSees (20\% mass loss).

can be modified based on the following empirical equation suggested by [16]:

$$
\sigma_{y}^{\prime}=\sigma_{y}(1-0.005 \psi),
$$

where $\psi$ is the percentage mass loss of the reinforcement.

4.2. Influence of Corrosion on Stiffness of Tie Reinforcement. In this study the stiffness of the horizontal ties of spiral reinforcement is computed using the following empirical equation suggested by [38]:

$$
K_{t}=\frac{4 E_{\mathrm{sp}} A_{\mathrm{sp}}^{\prime}}{\sqrt{\left(s^{2}+d_{c}^{2}\right)}},
$$

where $E_{\mathrm{sp}}$ is the elastic modulus, $A_{\mathrm{sp}}^{\prime}$ is the cross-sectional area of corroded spiral reinforcement, $s$ is the spiral pitch, and $d_{c}$ is the core diameter.

The focus of this paper is on circular columns. However, in the case of rectangular section, the axial stiffness of tie reinforcement can be computed using

$$
K_{t}=\frac{E_{\mathrm{st}} A_{\mathrm{st}}^{\prime}}{l_{t}}
$$

where $E_{\mathrm{st}}$ is the elastic modulus of tie reinforcement, $A_{\mathrm{st}}^{\prime}$ is the cross-sectional area of corroded tie reinforcement, and $l_{t}$ is the length of the rectangular tie reinforcement.

\section{Description of Uniaxial Material Models including Corrosion Damage}

5.1. Reinforcing Steel Model: Tension and Compression Envelopes. The uniaxial material model developed by [29] is used to model the reinforcing steel. This advanced material model combines the material nonlinearity with geometrical nonlinearity due to inelastic buckling into a single-material model. The impact of geometrical nonlinearity on cyclic behaviour of reinforcing bars is also considered. Moreover, the cyclic degradation due to low-cycle fatigue and the impact of corrosion on the tension and compression envelopes (including the postbuckling behaviour) are included. Further discussion about the model development is available in [29]. To implement the buckling model in OpenSees the uniaxial Hysteretic model available in OpenSees is modified and used (the detailed discussion is available in [25]). Figure 4 shows our proposed tension and compression envelope curves of corroded bars implemented in OpenSees.

5.2. Reinforcing Steel Model: Cyclic Response and Low-Cycle Fatigue Degradation. As explained in Section 5.1 the Hysteretic material model in OpenSees is modified to define the reinforcing steel model. The cyclic response of the Hysteretic model is defined by two pinch parameters (pinch $x$ and pinch $y$ ). The pinching effect in the cyclic response of reinforcing bars is affected by the stiffness of the horizontal tie reinforcement. The optimum values of pinch parameters have been obtained by a comprehensive parametric study reported in [25] (the calibrated values are pinch $x=0.4$ and pinch $y=0.6)$.

The Uniaxial Fatigue model is wrapped to the steel material model to model the low-cycle fatigue degradation of corroded vertical reinforcement. The low-cycle fatigue material constants are modified to account for the impact of corrosion on the low-cycle fatigue life of corroded bars based on the model developed by [29]. Figure 5 shows an example cyclic response of the implemented Hysteretic + Fatigue model for the uncorroded and corroded reinforcing steel. Further detailed discussion about modelling combined fatigue and buckling of reinforcing bars inside RC columns is available in [29].

5.3. Corrosion Damaged Confined Concrete Model. The compressive behaviour of confined concrete is a function of volumetric ratio, yield strength, and fracture strain of the horizontal tie reinforcement (i.e., spiral, hoop, and transverse reinforcement) $[39,40]$. Since tie reinforcement is the nearest to the surface, being exposed to chloride attack, they may 


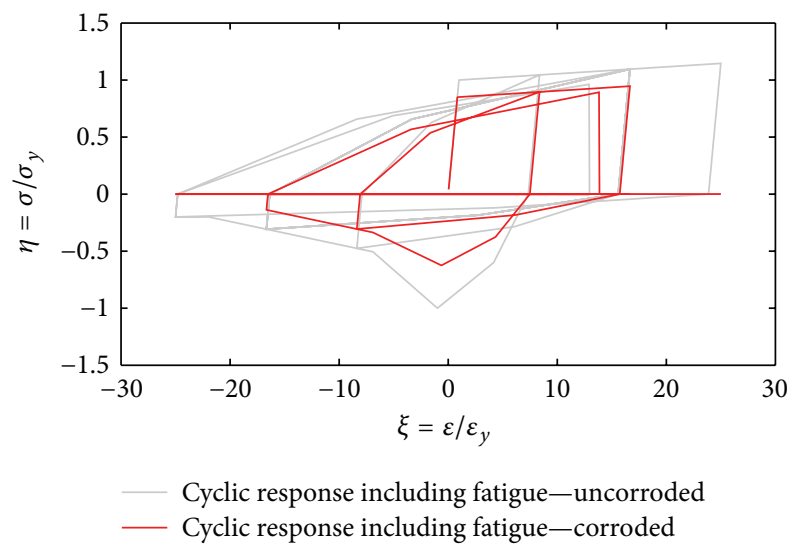

Figure 5: Cyclic response of the Hysteretic + Fatigue model in OpenSees (20\% mass loss).

start corroding prior to the corrosion initiation of vertical reinforcement. As a result the volumetric ratio of tie reinforcement is decreased due to cross section loss. There is also a reduced yield strength and fracture strain due to the pitting effect. Therefore, the internal confinement pressure of the core concrete can result in premature fracture of tie reinforcement.

To date, there has not been any experimental study to quantify and model the effect of corrosion on the nonlinear behaviour of confined concrete under monotonic compression and cyclic loading. Further research is required to understand and model the extent of corrosion damage on confined concrete behaviour. However, a simplified methodology is used in this research to modify the confined concrete material model (which is a function of the percentage mass loss in horizontal tie reinforcement) to account for the effect of corrosion damage.

In this study the uniaxial Concrete 04 material model available in OpenSees is used to model the concrete. The Popovics curve [41] is used for the compression envelope and the Karsan-Jirsa model [42] is used to determine the slope of the curve for unloading and reloading in compression. For tensile loading, an exponential curve is used to define the envelope to the stress-strain curve. Further details are available in [43].

The parameters proposed by [40] are used to model the effect of confinement on concrete in compression. The maximum compressive stress of the concrete $\left(\sigma_{\mathrm{cc}}\right)$ and the strain at the maximum compressive strain $\left(\varepsilon_{\mathrm{cc}}\right)$ can be calculated using the equations developed in [40].

The maximum crushing strain of the confined concrete is defined by the fracture of the first horizontal tie/spiral reinforcement. Here the model proposed by [44] is used to predict the concrete crushing strain as defined in

$$
\varepsilon_{\mathrm{cc}}=0.004+1.4\left(\frac{\rho_{\mathrm{sc}} \sigma_{y \mathrm{tie}} \varepsilon_{u \mathrm{tie}}}{\sigma_{c}}\right),
$$

where $\varepsilon_{u \text { tie }}$ is the fracture strain of the tie/spiral reinforcement, $\rho_{\mathrm{sc}}$ is the volumetric ratio of spiral reinforcement, and $\sigma_{y \text { tie }}$ is the yield stress of spiral reinforcement.

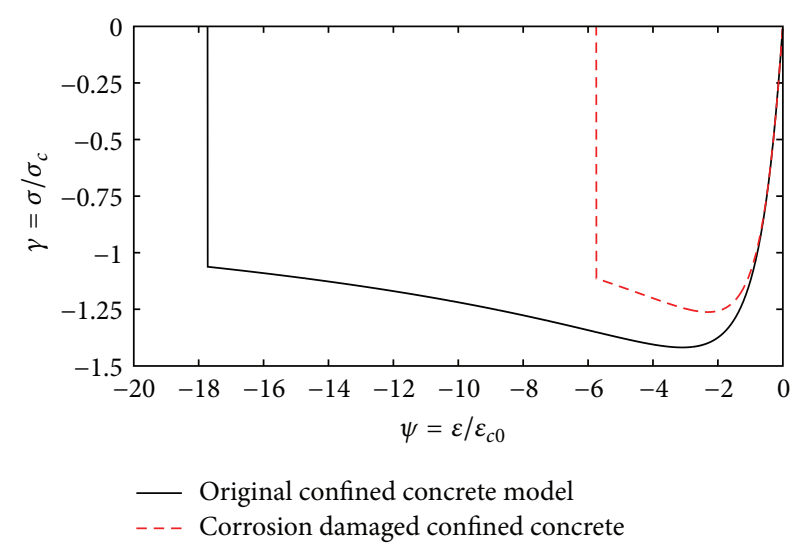

FIGURE 6: Corrosion damaged confined concrete model (20\% mass loss).

It is clear that the confined concrete model is a function of yield strength, volumetric ratio, and fracture strain of the confinement/tie reinforcement. Therefore, the previously defined equations for reinforcing steel can be used to modify the cross-sectional area, yield strength, and fracture strain of tie reinforcement as a function of the percentage mass loss. Accordingly these modified values can be used to account for the impact of corrosion on confined concrete model (Figure 6).

5.4. Corrosion Damaged Cracked Cover Concrete Model. Once corrosion initiates the corrosion products accumulate around the reinforcement. Given the volume of the corrosion products is bigger than the original reinforcing steel, it generates a radial pressure/expansion on the concrete surrounding the reinforcement. This behaviour is like a thick cylinder under internal pressure that eventually results in fracture of the cover concrete [45-47]. The cracking of cover concrete results in loss of compressive strength and crushing strain of the concrete in the compressive zone of RC sections. Therefore consideration needs to be given to model the influence of this cracking on the response of cover concrete in compression.

The response of cracked concrete in compression is described in detail by [48] which is known as compression field theory (CFT). Based on CFT the compressive strength of cracked concrete in compression depends on the magnitude of the average tensile strain in the transverse direction, which causes longitudinal microcracks. Reference [49] employed this method in nonlinear finite element analysis of corrosion damaged RC beams with modified constitutive model for the cracked cover concrete as a function of percentage mass loss and validated this against experimental results. Therefore, the equations suggested by [49] are employed to model the compression response of crack cover concrete. Figure 7(a) shows the compression envelope and Figure 7 (b) shows the tension envelope of the uniaxial material model for corrosion damaged unconfined cover concrete used in the fibre model. Further details are available in [49]. 


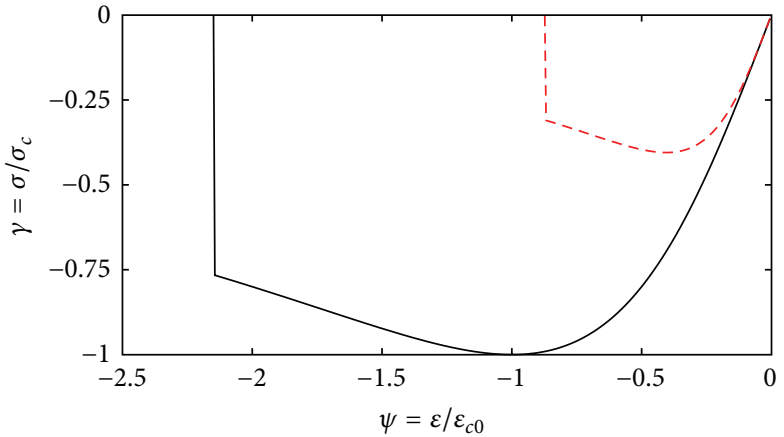

- Original unconfined concrete model
-- Corrosion induced crack unconfined concrete

(a)

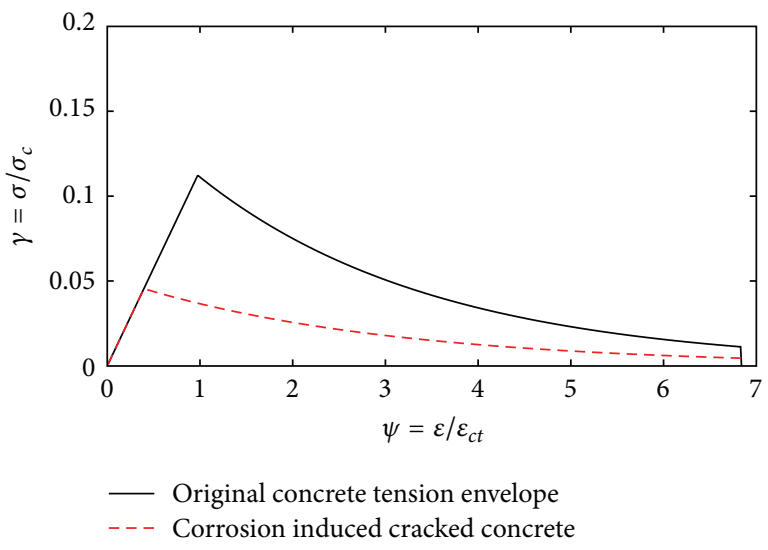

(b)

FIGURE 7: Corrosion damaged cracked cover concrete model for $20 \%$ mass loss: (a) compression; (b) tension.

5.5. Bond-Slip Model and Zero-Length Element. In seismic design of RC structures and bridges, plastic hinges are formed at the column/beam ends. This will induce a substantial strain penetration along the longitudinal bars into the joint that eventually results in slippage of longitudinal bars. This phenomenon has been observed by other researchers experimentally [50]. Reference [51] adopted a bar-slip model for the end slip of longitudinal reinforcement in beam-column joints. This model has been employed by [25] to model the cyclic behaviour of RC columns and is validated against UWPEER experimental RC column database [52].

Corrosion affects the reinforcing steel near the surface of the concrete due to diffusion of chloride ions from the surface and/or carbonation of cover concrete. In bridge piers, the vertical reinforcement bars are anchored to the foundation well below the foundation surface. Therefore, the vertical reinforcement does not corrode at this depth and the bar-slip behaviour of bars at the anchorage zone remains the same as in the uncorroded column. This has been observed by other researchers experimentally [12-14].

It should be pointed out that corrosion does affect the bond strength of corroded vertical reinforcement above the foundation level (internal bond-slip within the column itself). However, based on the observed experimental results, the reduced bond strength does not govern the failure of columns. References [12-14] reported that the failure of corroded columns and beams under cyclic loading is mainly govern by fracture of bars in tension due to low-cycle fatigue and buckling of bars and crushing of confined concrete in compression.

Reference [53] conducted a comprehensive detailed nonlinear finite element analysis of corroded RC beams and validated them against experimental results. They have reported that reduced bond strength only changes the crack pattern and affects the serviceability of corroded beams. They concluded that reduced bond strength does not affect the ultimate capacity of corroded beams. Therefore, bond-slip of corroded vertical bars within the element is not considered in this research.
The detailed discussion and implementation of the zerolength section in modelling the cyclic behaviour of RC columns is available in [25].

\section{Impact of Corrosion Damage on Nonlinear Response of RC Bridges Piers}

In this section the impact of different corrosion damage scenarios on the inelastic response of RC bridge piers is explored. A comparative study on two hypothetical corroded RC columns with different buckling lengths of vertical bars is conducted. The columns are taken from the UW-PEER experimental RC column database [52]. These columns are used to validate and calibrate the basic numerical model for the uncorroded columns [25].

To investigate the impact of corrosion on drift capacity and strength loss of RC columns a series of nonlinear pushover analyses with varied corrosion levels are conducted. To explore the impact of cyclic degradation, nonlinear cyclic analyses using the load history that was used in the experiment are conducted. In order to investigate the impact of different modelling techniques and damage mechanism for each analysis type three scenarios are considered:

(a) Vertical and horizontal tie reinforcement are corroded, but cover and core concrete are not affected by corrosion.

(b) Vertical and horizontal tie reinforcement are corroded and the cover concrete is cracked due to corrosion, but the core concrete is not affected.

(c) Vertical and horizontal tie reinforcement are corroded; the cover concrete is cracked and the core concrete is affected due to corrosion of confining/tie reinforcement.

These scenarios will highlight the importance of each damage component that needs to be considered in modelling nonlinear response of corroded RC columns. 


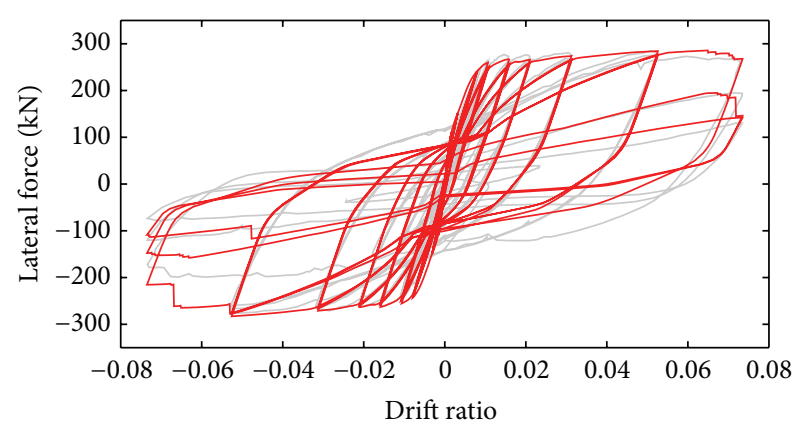

Experiment

- Fibre model

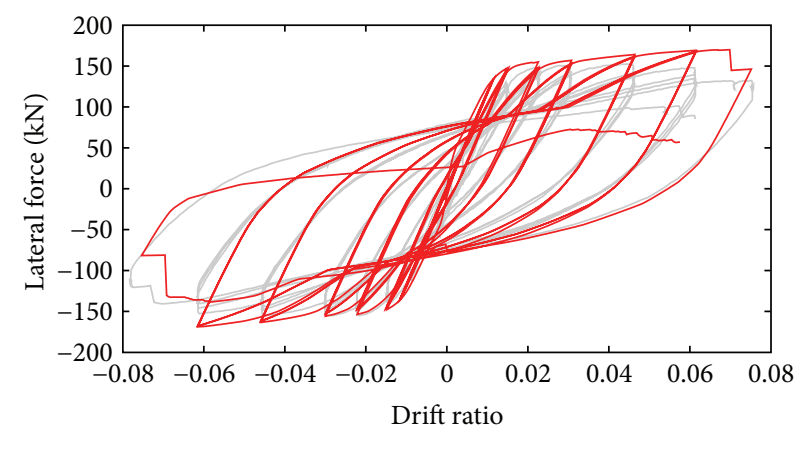

- Experiment

(a)

FIGURE 8: Comparison of experimental results and calibrated numerical model of uncorroded columns: (a) Lehman's column 415; (b) Moyer and Kowalsky's column 1.

Lehman's column 415 and Moyer and Kowalsky's column $1[50,54]$ are considered in this study. The geometrical details, material properties, and detailed experimental results of these columns are available in $[50,54]$. Figure 8 shows a comparison of the numerical model and experimental responses of these columns. It should be noted that Lehman's column 415 has $L_{\text {eff }} / d=10$ and Moyer and Kowalsky's column 1 has $L_{\text {eff }} / d=4$. The detailed discussion of the numerical model validation is available in [25]. It should be noted that the maximum drift capacity in this paper is considered as the point where the force-displacement response of the column starts softening and losing strength. It is found that the maximum drift capacity of both columns at uncorroded state is about $6 \%$.

The buckling lengths of corroded vertical reinforcement are calculated using the methodology described in Section 4. The corrosion of horizontal ties is considered in the buckling length calculation. As discussed previously (Section 4), the buckling length of the vertical bars is a function of the tie reinforcement's stiffness and the vertical reinforcement's flexural rigidity. Corrosion results in a reduction in flexural rigidity of vertical bars. Therefore, the required stiffness from tie reinforcement to restrain vertical bars against buckling is reduced. However, corrosion also reduces the stiffness of the tie reinforcement. For example, in Moyer and Kowalsky's column, the vertical reinforcement buckled between two ties. In this case, it was found that corrosion did not affect the buckling length.

In Lehman's column 415, the vertical reinforcement buckled over five ties. However, once the corrosion level exceeds $10 \%$, the buckling length reduced and the vertical reinforcement buckled over four ties. It should be noted that although the buckling length is reduced, $L_{\text {eff }} / d^{\prime}$ is not necessarily reduced, where $L_{\text {eff }}$ is the buckling length and $d^{\prime}$ is the diameter of the corroded vertical reinforcement. This is because corrosion also reduces the diameter of vertical bars. This change in buckling length is related to the relative corrosion level and stiffness between the vertical and tie reinforcement.
In practice, the horizontal tie reinforcement is closer than the main vertical reinforcement to the surface of concrete. Therefore, it might start corroding earlier than vertical reinforcement. This phenomenon might have an effect on the buckling length and confined concrete behaviour. However, there has not been any research to date to explore the correlation between the corrosion levels of the horizontal tie and vertical reinforcement. This is an area for future research and therefore, in this research, in the absence of any experimental/field data, the same corrosion is considered for both vertical and tie reinforcement.

It should be noted that the calculation of the time to corrosion initiation and time-dependent corrosion propagation is out of the scope of this paper. There are mathematical models available in the literature that enable an estimation of the time to corrosion initiation and propagation based on the environmental conditions $[55,56]$. The corrosion rate can also be measured on site by electrical equipment which can then be turned into a mass loss ratio using Faraday's law of electrolysis [57]. Given that the focus of this paper is on the impact of different mass loss ratios on the seismic performance of RC columns, the corrosion level is modelled by percentage mass loss throughout this paper.

\subsection{Scenario (a): Column Nonlinear Behaviour When Cor-} rosion Is Assumed Present in Vertical and Horizontal Tie Reinforcement Only. In this scenario, it is assumed that the corrosion damage is only limited to the steel reinforcement (vertical and horizontal tie reinforcement); that is, cover concrete is uncracked and corrosion of confining reinforcement does not affect the confined concrete behaviour. Here, the steel model described in Section 5.1 is used which includes the impact of corrosion on the buckling and postbuckling behaviour in compression and strength and ductility loss in tension.

Figure 9 shows the results of monotonic pushover analyses. Figure 9(a) shows that the failure mode of Lehman's column 415 is by vertical bar buckling and core confined 


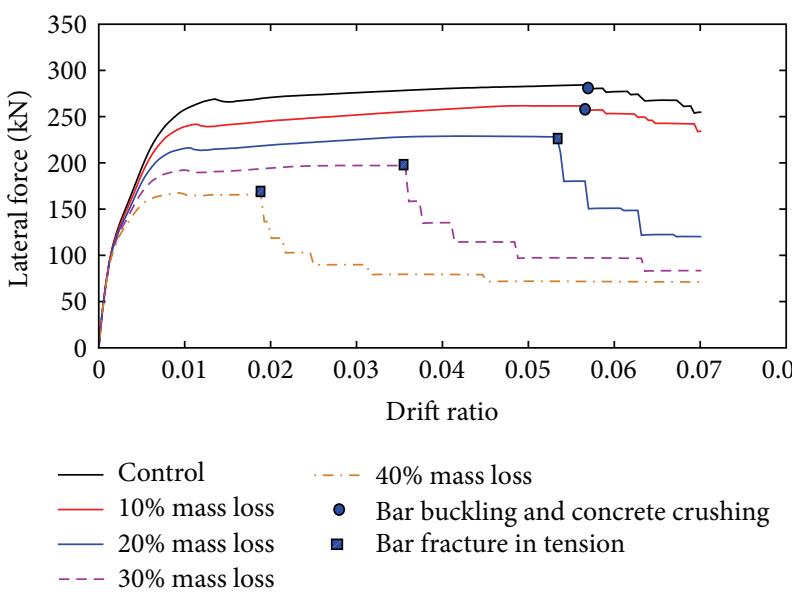

(a)

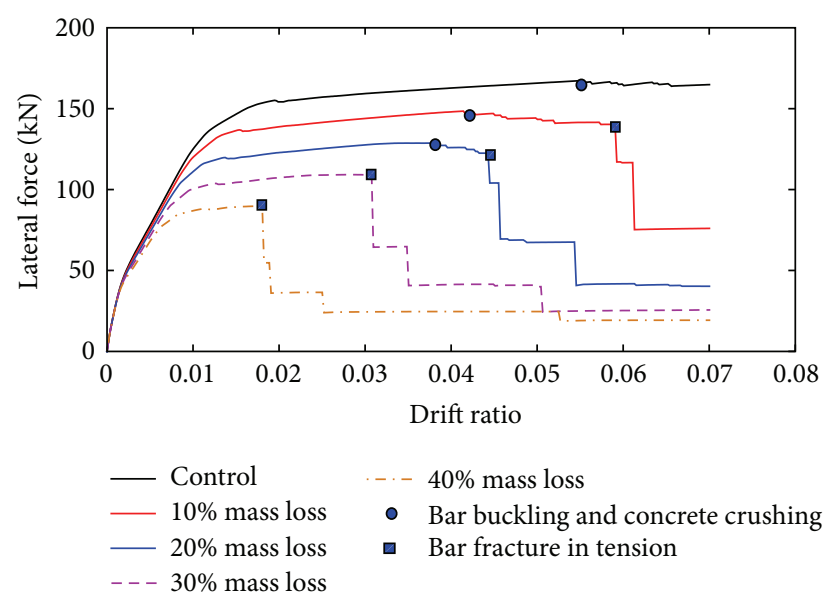

(b)

FIGURE 9: Pushover analyses considering corrosion induced damage in reinforcing steel: (a) Lehman's column 415; (b) Moyer and Kowalsky's column 1.

concrete crushing up to $10 \%$ mass loss. However, as the corrosion level increases beyond $10 \%$ mass loss, the failure mode changes from vertical bar bucking and concrete crushing in compression to fracture of the vertical bars in tension.

Figure 9(b) shows that Moyer and Kowalsky's column 1 has also failed in bar buckling and concrete crushing in compression. However, because $L_{\text {eff }} / d=4$, the strength loss is not as significant as that of Lehman's column 415 with $L_{\text {eff }} / d=10$ under monotonic loading. The corrosion level up to $20 \%$ mass loss changes Moyer and Kowalsky's column 1 behaviour. The failure initiates with bar buckling and concrete crushing in compression and followed by fracture of the vertical reinforcement in tension. With corrosion levels greater than $20 \%$ mass loss failure is by premature fracture of the vertical bars in tension. At this point a cascade of bar fracture can be seen in the graphs up to complete collapse of the columns.

Figures 10(a) and 10(b) show Lehman's column 415 with $10 \%$ and $20 \%$ mass losses under cyclic loading, respectively. Comparing the monotonic and cyclic responses (the same cyclic load protocol as the experiment) shows that low-cycle fatigue has a significant impact on the column response. The monotonic analysis showed that $10 \%$ mass loss did not result in vertical bar fracture in tension and the failure was governed by bar buckling and concrete crushing. However, in cyclic analysis, the failure mode is combined bar buckling and concrete crushing in compression (failure initiation) followed by bar fracture in tension due to low-cycle fatigue.

Here we have a system that does not technically fail in crushing and buckling but survives a little longer until the next cycle when the vertical reinforcement fails in tension. It was found that a mass loss ratio greater than $10 \%$ has a significant impact on the nonlinear response of the corroded column due to reduced low-cycle fatigue life. Figure 10(b) shows that at $20 \%$ mass loss resulted in bar fracture at 0.05 drift ratio in pushover analysis, but it resulted in bar fracture at $0.03 \mathrm{drift}$ ratio under cyclic loading due to low-cycle fatigue failure.
Figures 10(c) and 10(d) show a similar result for Moyer and Kowalsky's column 1. Overall, Moyer and Kowalsky's column 1 has slightly less pinched cyclic response. This is due to the influence of the buckling length of the vertical bars and its cyclic degradation due to buckling [25].

\subsection{Scenario (b): Column Nonlinear Behaviour When Corro-} sion Is Assumed Present in Vertical and Horizontal Tie Reinforcement and Cover Concrete Is Cracked. In this scenario, it is assumed that the reinforcing steel (vertical and tie) is corroded and the cover concrete is cracked due to corrosion of vertical reinforcement. The results of the pushover analyses are shown in Figure 11. The results in this case are almost identical to the previous case (Section 6.1) where the damage in cover concrete was not considered. Therefore in can be concluded that whether or not we seek to model the corrosion induced cracking of cover concrete it does not have a significant impact on the nonlinear response of corroded columns. Further discussion and comparison of this scenario with other damage scenarios are available in Section 6.3.

6.3. Scenario (c): Column Seismic Behaviour When Corrosion Is Assumed Present in Vertical and Horizontal Tie Reinforcement and Both Cover and Confined Concrete Are Damaged. In this scenario, it is assumed that the reinforcing steel (vertical and tie) is corroded, cover concrete is cracked, and the core confined concrete is affected by the corrosion of horizontal tie reinforcement (as described in Section 5.3). Figure 12(a) shows the results of monotonic pushover analyses of Lehman's column 415. The results show that the failure mechanism of this column for up to $10 \%$ mass loss is bar buckling and core confined concrete crushing in compression. However, for corrosion levels beyond $10 \%$, the failure mode changes. This is a loss of drift capacity which starts with bar buckling and concrete crushing in compression and it is followed by bar fracture in tension. These analyses demonstrate the importance of modelling the 


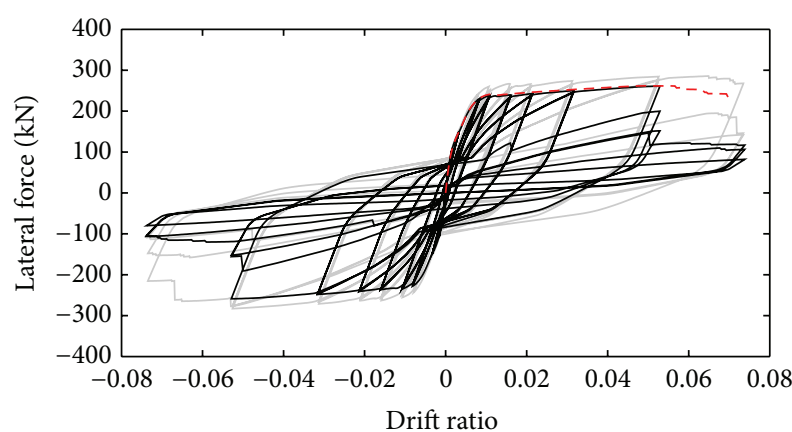

Cyclic response, uncorroded

- Cyclic response, $10 \%$ mass loss

- - - Pushover response, $10 \%$ mass loss

(a)

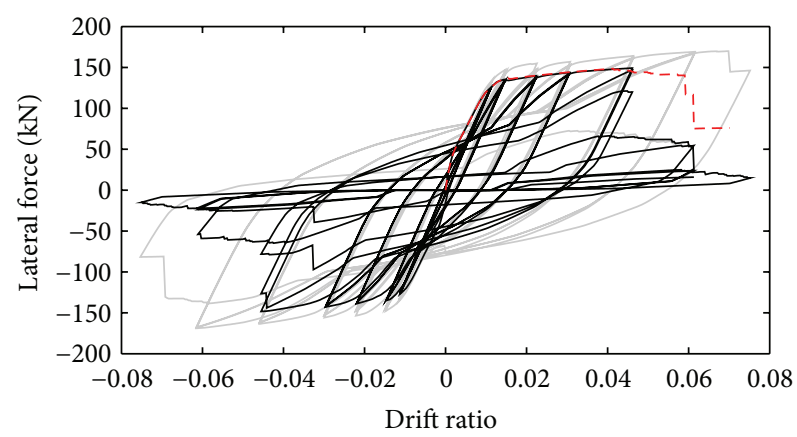

Cyclic response, uncorroded

Cyclic response, $10 \%$ mass loss

Pushover response, $10 \%$ mass loss

(c)

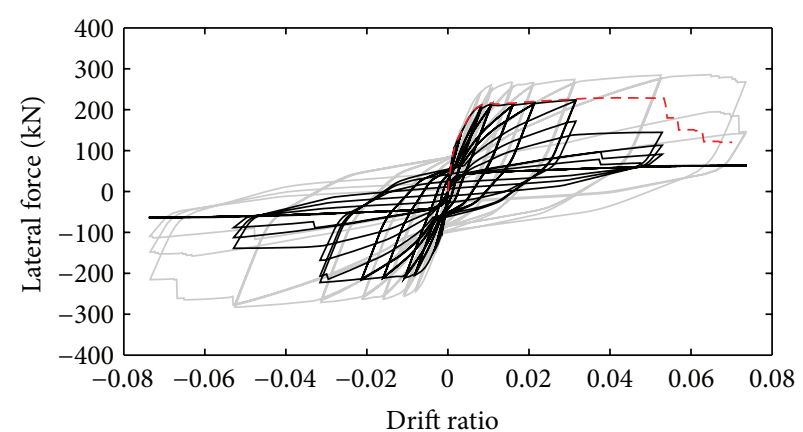

Cyclic response, uncorroded

- Cyclic response, $20 \%$ mass loss

- - - Pushover response, 20\% mass loss

(b)

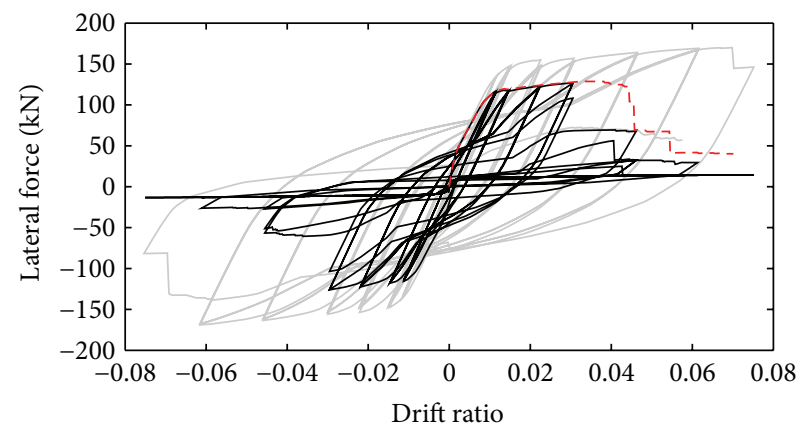

Cyclic response, uncorroded

- Cyclic response, 20\% mass loss

- - - Pushover response, 20\% mass loss

(d)

FIGURE 10: Cyclic analyses considering corrosion induced damage in reinforcing steel: (a) and (b) Lehman's column 415; (c) and (d) Moyer and Kowalsky's column 1.

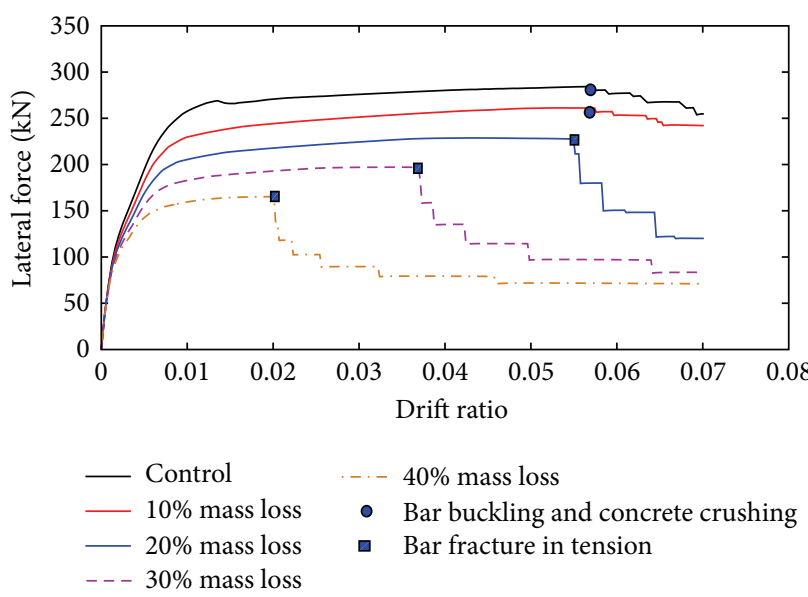

(a)

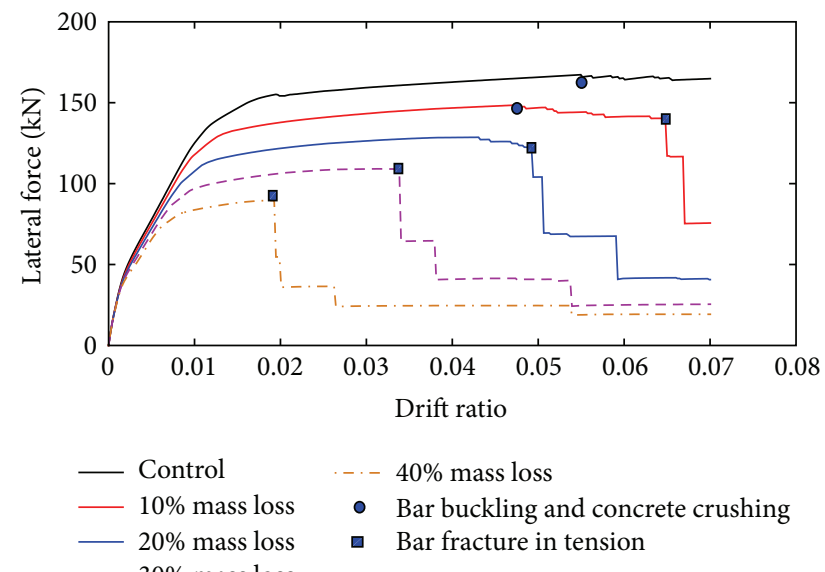

(b)

Figure 11: Pushover analyses considering corrosion induced damage in reinforcing steel and cracked cover concrete: (a) Lehman's column 415; (b) Moyer and Kowalsky's column 1. 


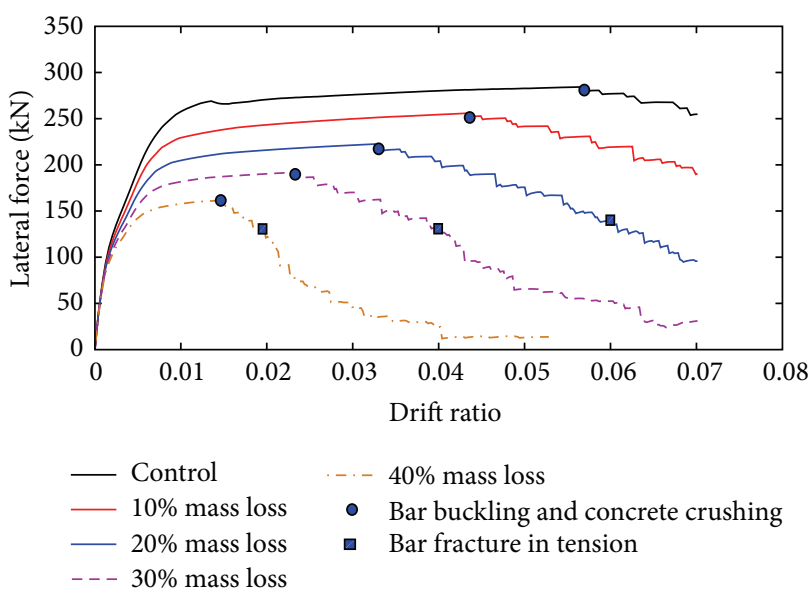

(a)

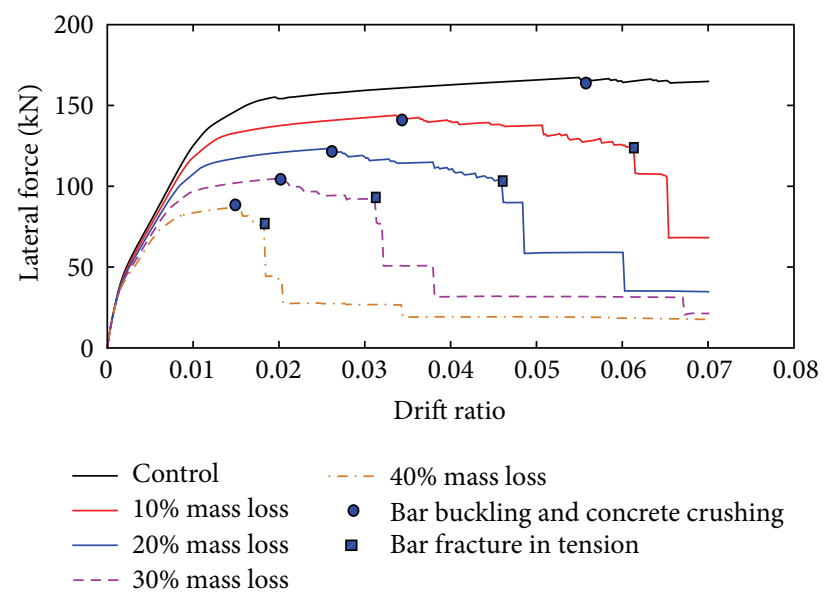

(b)

FIGURE 12: Pushover analyses considering corrosion induced damage in reinforcing steel, cracked cover concrete, and confined concrete: (a) Lehman's column 415; (b) Moyer and Kowalsky's column 1.

influence of corrosion on the confined concrete (through loss of confining tie reinforcement). This corrosion damage on the confined concrete results in a rapid reduction in strength and ductility of the corroded columns compared to the previous cases where confined concrete was considered to be undamaged.

Figure 12(b) shows the results of pushover analyses of Moyer and Kowalsky's column 1. In this case, the failure mode was mainly bar buckling and concrete crushing followed by fracture of bars in tension for up to $20 \%$ mass loss. However, corrosion levels beyond 20\% mass loss have changed the failure mode to premature fracture of bars in tension. This difference between the behaviour of the two columns is due to the buckling behaviour of the vertical bars. Given that Moyer and Kowalsky's column 1 has much smaller buckling length the strength degradation in compression is much smaller than Lehman's column 415. Therefore, corrosion has more a significant impact in terms of ductility loss of bars in tension whereas in Lehman's column 415 failure initiates with severe bar buckling and concrete crushing; then it is followed by fracture of vertical bars in tension.

Figure 13 shows the results of cyclic analysis. It shows the cyclic analyses of Lehman's column 415 and Moyer and Kowalsky's column 1 with $10 \%$ and $20 \%$ mass loss together with the corresponding pushover envelopes. Figure 13 shows that the extent of corrosion damage under cyclic loading is more severe than monotonic loading. The results of monotonic analysis showed that considering the ductility loss of corroded bars in tension and confinement reinforcement in compression has a big impact on bar buckling and fracture of reinforcement. However, cyclic analysis results show that considering cyclic degradation due to low-cycle fatigue is crucial to have a realistic evaluation of the seismic performance of existing corroded columns.

For example, in Figures 13(a) and 13(b), the failure of Lehman's column 415 was governed by bar buckling and concrete crushing for a corrosion level up to $10 \%$ under monotonic loading. However, the same corrosion level results in a much more severe drift capacity loss under cyclic loading due to a reduced low-cycle fatigue life. Similarly in Figures 13(c) and 13(d) the failure of Moyer and Kowalsky's column was governed by concrete crushing in compression followed by bar fracture in tension. However, low-cycle fatigue degradation due to cyclic loading results in premature fracture of bars and subsequently severe loss of drift capacity.

\section{Comparison of the Nonlinear Responses of Corroded Columns Computed in Different Scenarios}

In order to clearly demonstrate the significance of corrosion models, on the inelastic response of RC columns, a comparison between the computed responses of two columns with different scenarios has been made. The responses of columns with $20 \%$ mass loss in monotonic pushover and cyclic analyses are compared and shown in Figure 14.

Figure 14 shows the monotonic pushover and cyclic responses of Lehman's column 415 and Moyer and Kowalsky's column 1 with $20 \%$ mass losses and different corrosion damage models. Figures 14(a) and 14(b) show that if the corrosion induced damage to confined concrete is ignored, the predicted failure mode is likely to be the fracture of bars in tension due to their reduced ductility. However, if the corrosion induced damage to confined concrete is added, Figure 14(a) shows that the failure mode of Lehman's column 415 will change to concrete crushing and buckling of the vertical bars in compression.

Figure 14(b) shows that the failure mode of Moyer and Kowalsky's column 1 initiates with concrete crushing and buckling of bars in compression and then it is followed by fracture of bars in tension. This difference in failure mechanism is due to the differences in confinement level, the buckling length of the vertical bars, the ratio of longitudinal reinforcement, and the axial force ratio on the column. Therefore, in order to predict the nonlinear response accurately, a detailed finite element model is required. 


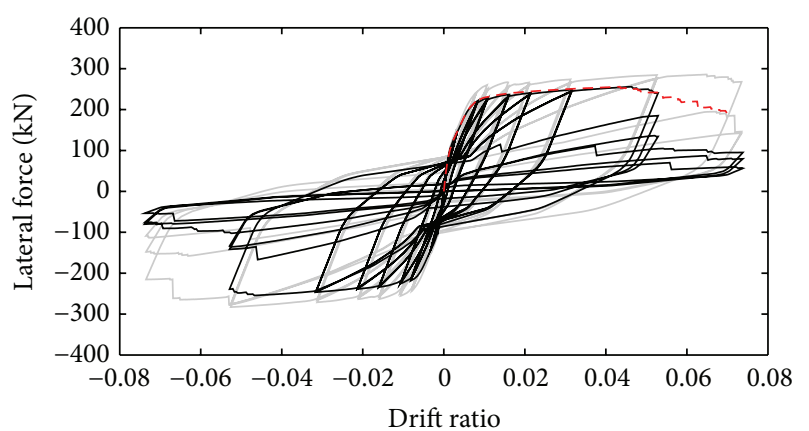

Cyclic response, uncorroded

- Cyclic response, $10 \%$ mass loss

- - - Pushover response, $10 \%$ mass loss

(a)

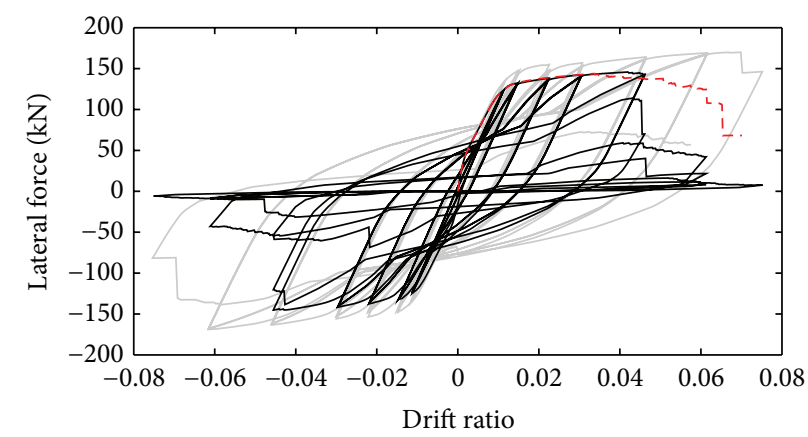

- Cyclic response, uncorroded

- Cyclic response, 10\% mass loss

- - - Pushover response, $10 \%$ mass loss

(c)

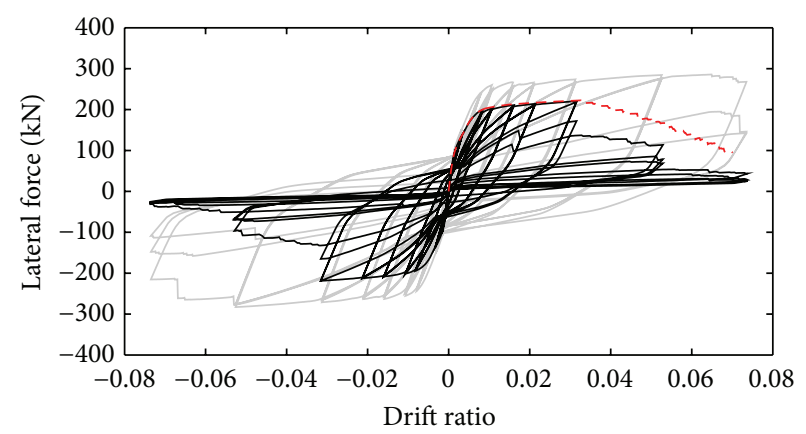

Cyclic response, uncorroded

- Cyclic response, $20 \%$ mass loss

- - - Pushover response, 20\% mass loss

(b)

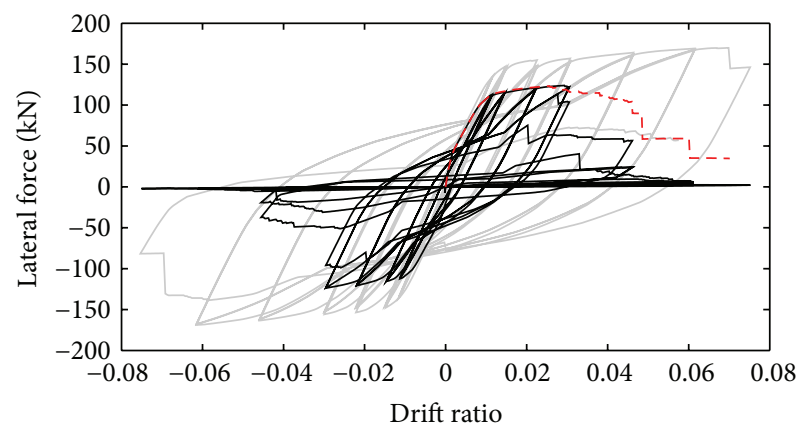

Cyclic response, uncorroded

- Cyclic response, 20\% mass loss

- - - Pushover response, 20\% mass loss

(d)

FIGURE 13: Cyclic analyses considering corrosion induced damage in reinforcing steel, cracked cover concrete, and confined concrete: (a) and (b) Lehman's column 415; (c) and (d) Moyer and Kowalsky's column 1.

It is found that the failure mode under cyclic loading is mainly governed by the fracture of horizontal bars in tension due to reduced low-cycle fatigue life (Figures 14(c) and 14(d)). This is a very important finding as it suggests that nonlinear quasistatic pushover analysis, on its own, is not adequate for performance assessment of existing corroded bridge piers.

With reference to Figure 14, it is evident that considering the impact of the corrosion damage on core confined concrete and low-cycle fatigue degradation is crucial. Therefore, they need to be considered when modelling the nonlinear behaviour of corrosion damaged RC bridge piers under seismic loading. This finding is in good agreement with the observed experimental results by other researchers [12-14, 58].

A series of experimental studies were conducted in [12] on the cyclic behaviour of large-scale corroded cantilever RC beams. Ou et al. found that as the level of corrosion increases the flexural failure initiates with premature buckling of longitudinal bars. This conclusion is in good agreement with the numerical results discussed in this paper. In another study [13] a series of experimental studies were conducted on cyclic behaviour of corroded RC columns with varied axial force. $\mathrm{Ma}$ et al. have reported that once the corrosion level increases beyond about $14 \%$ rapid strength and ductility reduction and cyclic degradation in hysteretic loops are seen due to reduced low-cycle fatigue life and premature buckling of vertical reinforcement. This conclusion is in good agreement with the predicted failure modes using the numerical model presented in this paper.

The detailed finite element model developed in this paper can accurately model the nonlinear behaviour of corroded RC columns subject to cyclic loading up to complete collapse. There is a need to extend the PEER-UW column database to include corroded RC columns so that further calibration/validation of the material model parameters can be performed. However, the modelling technique developed in this paper is able to simulate the multiple failure modes of corroded RC columns simultaneously. It represents the current state of the art and as such they provide a novel computational framework for the seismic response prediction of corroded RC bridges.

\section{Conclusions}

A series of pushover and cyclic analyses on two hypothetical corroded RC columns are conducted and these are used 


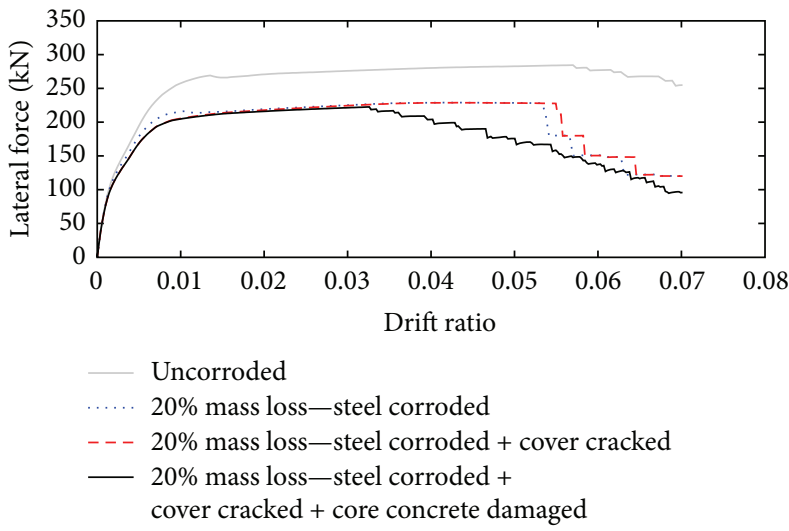

(a)

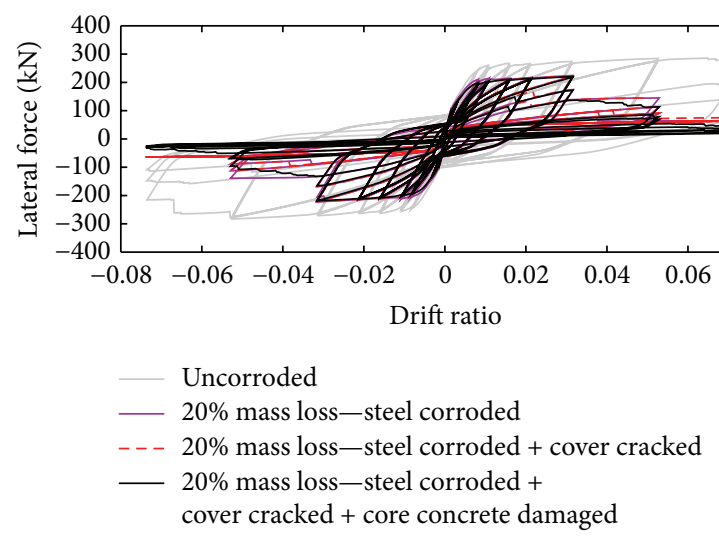

(c)

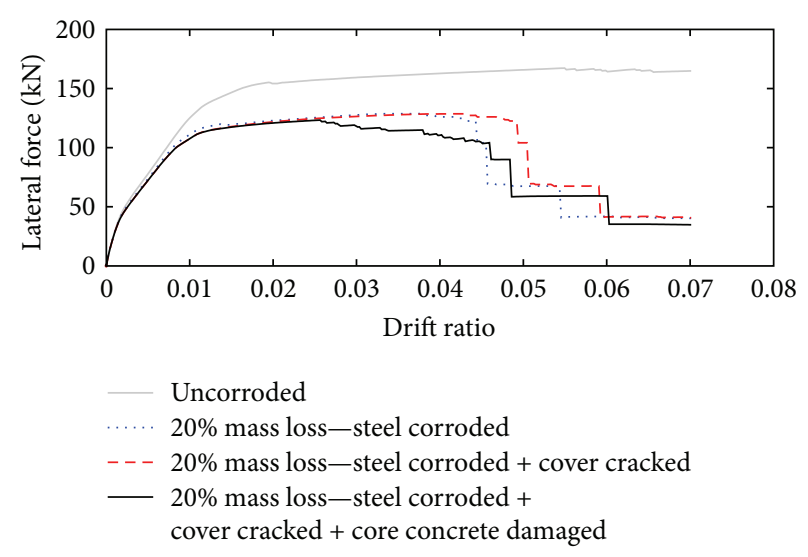

(b)

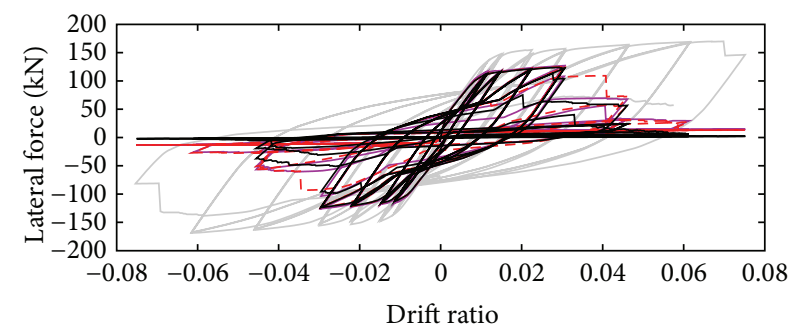

Uncorroded

$$
\begin{array}{ll}
- & 20 \% \text { mass loss-steel corroded } \\
--- & 20 \% \text { mass loss-steel corroded + cover cracked } \\
- & 20 \% \text { mass loss-steel corroded }+ \\
& \text { cover cracked + core concrete damaged }
\end{array}
$$

(d)

Figure 14: Comparison of the computed responses of columns with different deterioration models: (a) and (c) Lehman's column 415 under monotonic and cyclic loading; (b) and (d) Moyer and Kowalsky's column 1 under monotonic and cyclic loading.

to explore the performance of the proposed computational framework. The impact of corrosion on (i) the vertical reinforcing steel, (ii) the tie/confinement (iii) the cover (unconfined) concrete, and (iv) the core (confined) concrete is represented through new material models. The proposed new steel material model accounts for (i) inelastic nonlinear buckling of the vertical reinforcement, (ii) the corrosion loss of area, (iii) the nonuniform corrosion pitting, and (iv) lowcycle high amplitude fatigue. The new cover concrete material model includes the influence of internal pressure due to the build-up of corrosion products (using compression field theory). The new core concrete model includes the influence of corrosion induced loss of confining reinforcement. follows.

The main outcomes of this study can be summarised as

(1) Corrosion has a more significant impact on the ductility loss (drift capacity) of RC columns than the strength loss (plastic moment capacity).

(2) The numerical model developed in this paper is able to predict the nonlinear flexural response of corroded RC columns up to complete collapse. Results show, which depends on a cyclic load history, that flexural failure can be initiated by the buckling of vertical bars and crushing of core concrete which is then followed by fracture of bars in tension. In cases where the buckling of bars is not an issue or the buckling length is too short $\left(L_{\text {eff }} / d^{\prime} \leq 5\right)$ the failure is governed by the fracture of the vertical bars in tension due to low-cycle high amplitude fatigue.

(3) The analyses results show that, for the seismic performance and evaluation of existing corroded bridges, monotonic pushover analysis is not sufficient. The cyclic degradation due to low-cycle high amplitude fatigue has a significant influence on the response of corroded RC columns.

(4) The results of this study show that it is inadequate to assume that corrosion only affects the main vertical reinforcement in the column. It was found that the confined concrete with corroded confinement reinforcement starts crushing much faster than uncorroded undamaged concrete. This changes the failure mode and results in premature buckling of the vertical reinforcement. This change in the failure mode cannot be predicted if the damage in core confined concrete due to corrosion of tie reinforcement is ignored. This is in good agreement with observed 
experimental results reported by other researchers [12-14].

(5) The modelling technique developed in this paper has significantly improved the earlier models and can be used by other researchers in the future research for seismic vulnerability and fragility analysis of corroded RC bridges.

\section{Disclosure}

Any findings, opinions, and recommendations provided in this paper are only based on the authors' view.

\section{Competing Interests}

The authors declare that they have no competing interests.

\section{Acknowledgments}

This research is conducted in collaboration with the University of Bristol and the University of Washington while the first author was on sabbatical leave in the US. The funding provided by the World Wide University Network through the Research Mobility Program to the first author was much appreciated. The authors would like to thank Professor Marc O. Eberhard and Professor John F. Stanton for providing valuable guidance during the course of this research.

\section{References}

[1] S. Hida, F. I. S. Ibrahim, H. A. Capers et al., "Assuring bridge safety and serviceability in Europe," Tech. Rep. FHWAPL-10-014, Office of International Programs Federal Highway Administration US Department of Transportation American Association of State Highway and Transportation Officials, 2010.

[2] ASCE, Failure to Act: The Economic Impact of Current Investment Trends in Surface Transportation Infrastructure, Economic Development Research Group Inc: ASCE, 2011.

[3] D.-E. Choe, P. Gardoni, D. Rosowsky, and T. Haukaas, "Probabilistic capacity models and seismic fragility estimates for RC columns subject to corrosion," Reliability Engineering and System Safety, vol. 93, no. 3, pp. 383-393, 2008.

[4] L. Berto, R. Vitaliani, A. Saetta, and P. Simioni, "Seismic assessment of existing RC structures affected by degradation phenomena," Structural Safety, vol. 31, no. 4, pp. 284-297, 2009.

[5] J. Ghosh and J. E. Padgett, "Aging considerations in the development of time-dependent seismic fragility curves," Journal of Structural Engineering, vol. 136, no. 12, pp. 1497-1511, 2010.

[6] A. Alipour, B. Shafei, and M. Shinozuka, "Performance evaluation of deteriorating highway bridges located in high seismic areas," Journal of Bridge Engineering, vol. 16, no. 5, pp. 597-611, 2011.

[7] F. Biondini, E. Camnasio, and A. Palermo, "Lifetime seismic performance of concrete bridges exposed to corrosion," Structure and Infrastructure Engineering, vol. 10, no. 7, pp. 880-900, 2014.
[8] M. Akiyama, D. M. Frangopol, and H. Matsuzaki, "Life-cycle reliability of RC bridge piers under seismic and airborne chloride hazards," Earthquake Engineering and Structural Dynamics, vol. 40, no. 15, pp. 1671-1687, 2011.

[9] F. Biondini, A. Palermo, and G. Toniolo, "Seismic performance of concrete structures exposed to corrosion: case studies of lowrise precast buildings," Structure and Infrastructure Engineering, vol. 7, no. 1-2, pp. 109-119, 2011.

[10] C. K. Chiu, F. J. Tu, and F. P. Hsiao, "Lifetime seismic performance assessment for chloride-corroded reinforced concrete buildings," Structure and Infrastructure Engineering, vol. 11, no. 3, pp. 345-362, 2015.

[11] M. Sanchez-Silva, G.-A. Klutke, and D. V. Rosowsky, "Life-cycle performance of structures subject to multiple deterioration mechanisms," Structural Safety, vol. 33, no. 3, pp. 206-217, 2011.

[12] Y.-C. Ou, L.-L. Tsai, and H.-H. Chen, "Cyclic performance of large-scale corroded reinforced concrete beams," Earthquake Engineering and Structural Dynamics, vol. 41, no. 4, pp. 593-604, 2012.

[13] Y. Ma, Y. Che, and J. Gong, "Behavior of corrosion damaged circular reinforced concrete columns under cyclic loading," Construction and Building Materials, vol. 29, pp. 548-556, 2012.

[14] A. Meda, S. Mostosi, Z. Rinaldi, and P. Riva, "Experimental evaluation of the corrosion influence on the cyclic behaviour of RC columns," Engineering Structures, vol. 76, pp. 112-123, 2014.

[15] A. A. Almusallam, "Effect of degree of corrosion on the properties of reinforcing steel bars," Construction and Building Materials, vol. 15, no. 8, pp. 361-368, 2001.

[16] Y. G. Du, L. A. Clark, and A. H. C. Chan, "Residual capacity of corroded reinforcing bars," Magazine of Concrete Research, vol. 57, no. 3, pp. 135-147, 2005.

[17] Y. G. Du, L. A. Clarkt, and A. H. C. Chan, "Effect of corrosion on ductility of reinforcing bars," Magazine of Concrete Research, vol. 57, no. 7, pp. 407-419, 2005.

[18] J. Cairns, G. A. Plizzari, Y. Du, D. W. Law, and C. Franzoni, "Mechanical properties of corrosion-damaged reinforcement," ACI Materials Journal, vol. 102, no. 4, pp. 256-264, 2005.

[19] C. A. Apostolopoulos, M. P. Papadopoulos, and S. G. Pantelakis, "Tensile behavior of corroded reinforcing steel bars BSt 500s," Construction and Building Materials, vol. 20, no. 9, pp. 782-789, 2006.

[20] C. A. Apostolopoulos, "Mechanical behavior of corroded reinforcing steel bars S500s tempcore under low cycle fatigue," Construction and Building Materials, vol. 21, no. 7, pp. 1447-1456, 2007.

[21] M. M. Kashani, A. J. Crewe, and N. A. Alexander, "Nonlinear stress-strain behaviour of corrosion-damaged reinforcing bars including inelastic buckling," Engineering Structures, vol. 48, pp. 417-429, 2013.

[22] M. M. Kashani, A. J. Crewe, and N. A. Alexander, "Nonlinear cyclic response of corrosion-damaged reinforcing bars with the effect of buckling," Construction and Building Materials, vol. 41, pp. 388-400, 2013.

[23] M. M. Kashani, A. J. Crewe, and N. A. Alexander, "Use of a 3D optical measurement technique for stochastic corrosion pattern analysis of reinforcing bars subjected to accelerated corrosion," Corrosion Science, vol. 73, pp. 208-221, 2013.

[24] M. M. Kashani, L. N. Lowes, A. J. Crewe, and N. A. Alexander, "Finite element investigation of the influence of corrosion pattern on inelastic buckling and cyclic response of corroded reinforcing bars," Engineering Structures, vol. 75, pp. 113-125, 2014. 
[25] M. M. Kashani, Seismic performance of corroded $r c$ bridge piers: development of a multi-mechanical nonlinear fibre beam-column model [Ph.D. thesis], University of Bristol, Bristol, UK, 2014.

[26] E. Spacone, F. C. Filippou, and F. F. Taucer, "Fibre beam-column model for non-linear analysis of R/C frames: part I. Formulation," Earthquake Engineering and Structural Dynamics, vol. 25, no. 7, pp. 711-725, 1996.

[27] E. Spacone, F. C. Filippou, and F. F. Taucer, "Fibre beam-column model for non-linear analysis of R/C frames: part II. Applications," Earthquake Engineering and Structural Dynamics, vol. 25, no. 7, pp. 727-742, 1996.

[28] The Open System for Earthquake Engineering Simulation (OpenSees), Pacific Earthquake Engineering Research Centre, University of California, Berkeley, Berkeley, Calif, USA, 2011.

[29] M. M. Kashani, L. N. Lowes, A. J. Crewe, and N. A. Alexander, "Phenomenological hysteretic model for corroded reinforcing bars including inelastic buckling and low-cycle fatigue degradation," Computers and Structures, vol. 156, article 5393, pp. 58-71, 2015.

[30] J. Coleman and E. Spacone, "Localization issues in force-based frame elements," Journal of Structural Engineering, vol. 127, no. 11, pp. 1257-1265, 2001.

[31] J. S. Pugh, Numerical simulation of walls and seismic design recommendations for walled buildings [Ph.D. thesis], University of Washington, Seattle, Wash, USA, 2012.

[32] D. V. Val and R. E. Melchers, "Reliability of deteriorating RC slab bridges," Journal of Structural Engineering, vol. 123, no. 12, pp. 1638-1644, 1997.

[33] M. S. Darmawan and M. G. Stewart, "Effect of pitting corrosion on capacity of prestressing wires," Magazine of Concrete Research, vol. 59, no. 2, pp. 131-139, 2007.

[34] R. P. Dhakal and K. Maekawa, "Reinforcement stability and fracture of cover concrete in reinforced concrete members," Journal of Structural Engineering, vol. 128, no. 10, pp. 1253-1262, 2002.

[35] C. Lee, J. F. Bonacci, M. D. A. Thomas et al., "Accelerated corrosion and repair of reinforced concrete columns using carbon fibre reinforced polymer sheets," Canadian Journal of Civil Engineering, vol. 27, no. 5, pp. 941-948, 2000.

[36] W. Aquino, Long-term performance of seismically rehabilitated corrosion-damaged columns [Ph.D. thesis], University of Illinois at Urbana-Champaign, Champaign, Ill, USA, 2002.

[37] S. Timoshenko and J. Gere, Theory of Elastic Stability, MacGraw-Hill, New York, NY, USA, 1963.

[38] S. J. Pantazopoulou, "Detailing for reinforcement stability in RC members," Journal of Structural Engineering, vol. 124, no. 6, pp. 623-632, 1998.

[39] J. B. Mander, M. J. N. Priestley, and R. Park, "Observed stressstrain behavior of confined concrete," Journal of Structural Engineering, vol. 114, no. 8, pp. 1827-1849, 1988.

[40] J. B. Mander, M. J. Priestley, and R. Park, "Theoretical stressstrain model for confined concrete," Journal of Structural Engineering (United States), vol. 114, no. 8, pp. 1804-1826, 1988.

[41] S. Popovics, "A numerical approach to the complete stress-strain curve of concrete," Cement and Concrete Research, vol. 3, no. 5, pp. 583-599, 1973.

[42] I. D. Karsan and J. O. Jirsa, "Behavior of concrete under compressive loading," Journal of Structural Division, vol. 95, article ST12, 1969.

[43] M. P. Berry and M. O. Eberhard, "Performance modeling strategies for modern reinforced concrete bridge columns," PEER
Research Report, University of California, Berkeley, Berkeley, Calif, USA, 2006.

[44] B. D. Scott, R. Park, and M. J. N. Priestley, "Stress-strain behavior of concrete confined by overlapping hoops at low and high strain rates," Journal of the American Concrete Institute, vol. 79, no. 1, pp. 13-27, 1982.

[45] A. S. Al-Harthy, M. G. Stewart, and J. Mullard, "Concrete cover cracking caused by steel reinforcement corrosion," Magazine of Concrete Research, vol. 63, no. 9, pp. 655-667, 2011.

[46] T. Vidal, A. Castel, and R. François, "Analyzing crack width to predict corrosion in reinforced concrete," Cement and Concrete Research, vol. 34, no. 1, pp. 165-174, 2004.

[47] F. J. Molina, C. Alonso, and C. Andrade, "Cover cracking as a function of rebar corrosion: part 2-numerical model," Materials and Structures, vol. 26, no. 9, pp. 532-548, 1993.

[48] F. J. Vecchio and M. P. Collins, "The modified compressionfield theory for reinforced concrete elements subjected to shear," Journal of the American Concrete Institute, vol. 83, no. 2, pp. 219231, 1986.

[49] D. Coronelli and P. Gambarova, "Structural assessment of corroded reinforced concrete beams: modeling guidelines," Journal of Structural Engineering, vol. 130, no. 8, pp. 1214-1224, 2004.

[50] D. E. Lehman and J. P. Moehle, "Seismic performance of wellconfined concrete columns," PEER Research Report, University of California at Berkeley, 2000.

[51] L. N. Lowes and A. Altoontash, "Modeling reinforced-concrete beam-column joints subjected to cyclic loading," Journal of Structural Engineering, vol. 129, no. 12, pp. 1686-1697, 2003.

[52] M. Berry, M. Parrish, and M. Eberhard, "Performance database User's manual," in Pacific Earthquake Engineering Research Centre 2004, University of California at Berkeley, 2004, http://www.ce.washington.edu/ peeral/.

[53] A. N. Kallias and M. Imran Rafiq, "Finite element investigation of the structural response of corroded RC beams," Engineering Structures, vol. 32, no. 9, pp. 2984-2994, 2010.

[54] M. J. Moyer and M. J. Kowalsky, "Influence of tension strain on buckling of reinforcement in concrete columns," ACI Structural Journal, vol. 100, no. 1, pp. 75-85, 2003.

[55] K. A. T. Vu and M. G. Stewart, "Structural reliability of concrete bridges including improved chloride-induced corrosion models," Structural Safety, vol. 22, no. 4, pp. 313-333, 2000.

[56] D. V. Val, "Factors affecting life-cycle cost analysis of RC structures in chloride contaminated environments," Journal of Infrastructure Systems, vol. 13, no. 2, pp. 135-143, 2007.

[57] J. P. Broomfield, Corrosion of Steel in Concrete, Taylor \& Francis, London, UK, 2nd edition, 2007.

[58] M. M. Kashani, P. Alagheband, R. Khan, and S. Davis, "Impact of corrosion on low-cycle fatigue degradation of reinforcing bars with the effect of inelastic buckling," International Journal of Fatigue, vol. 77, pp. 174-185, 2015. 

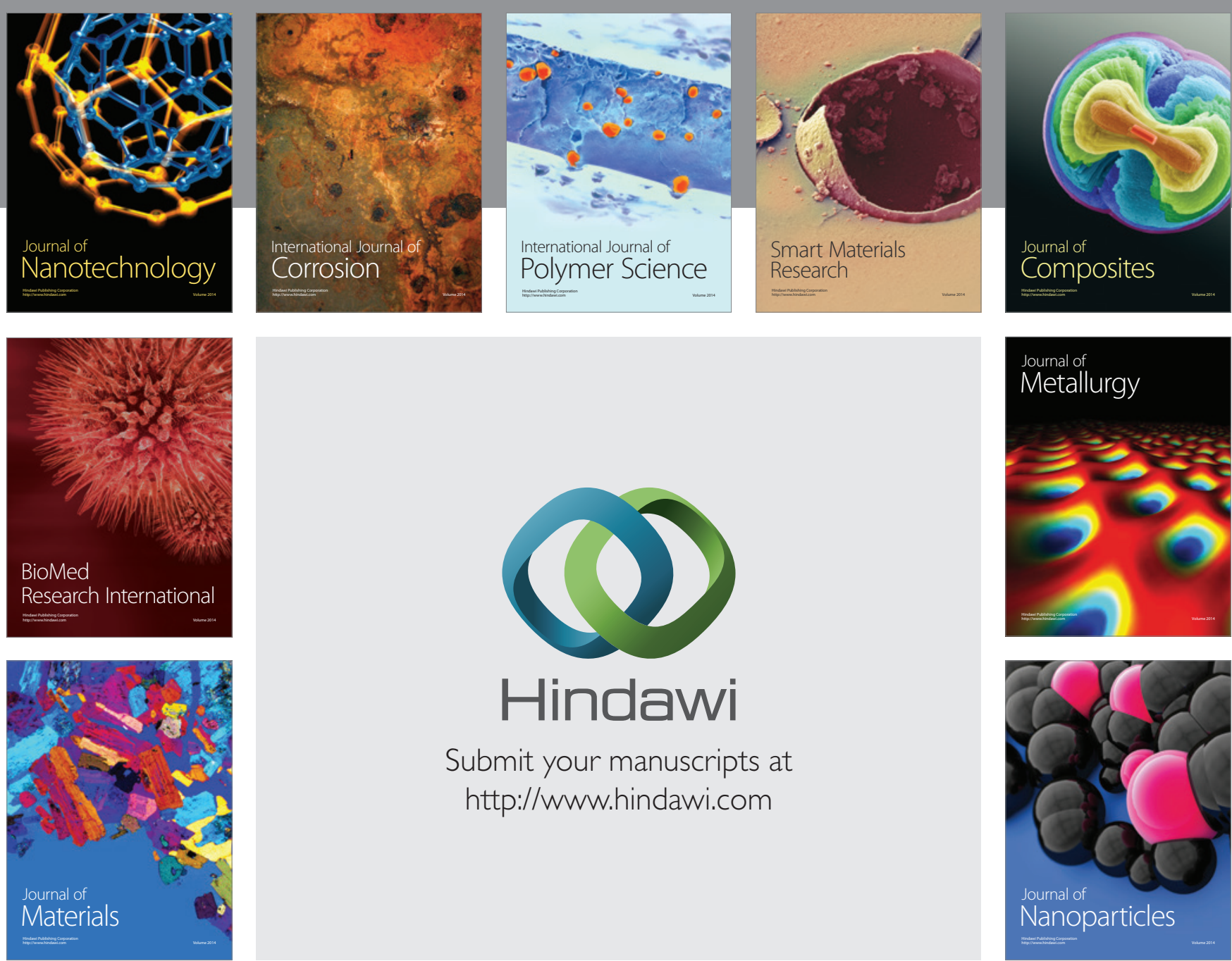

\section{Hindawi}

Submit your manuscripts at

http://www.hindawi.com

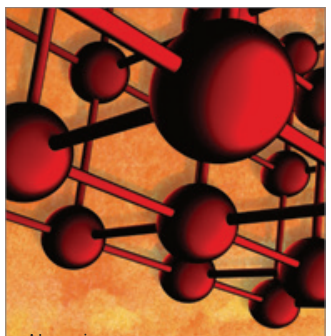

Materials Science and Engineering
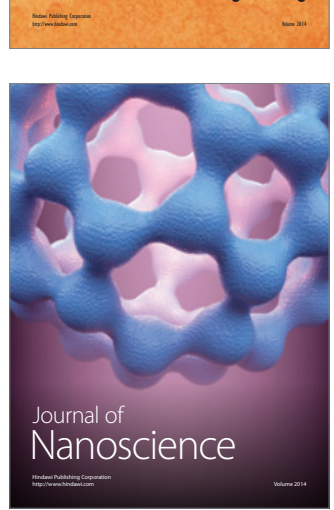
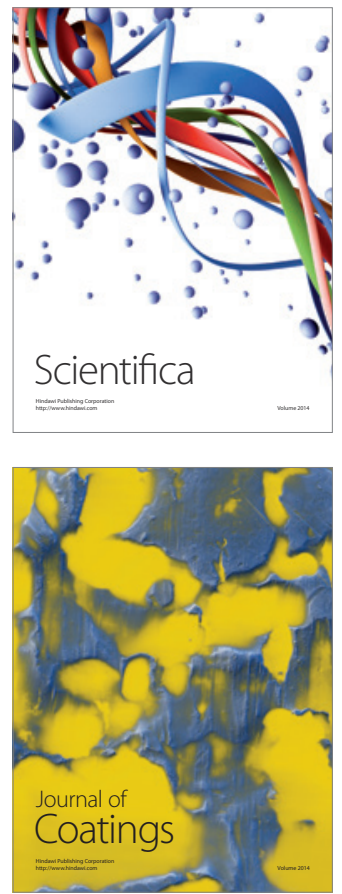
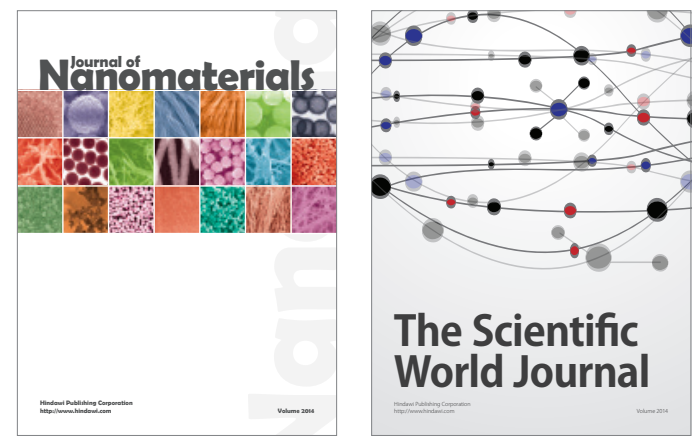

The Scientific World Journal
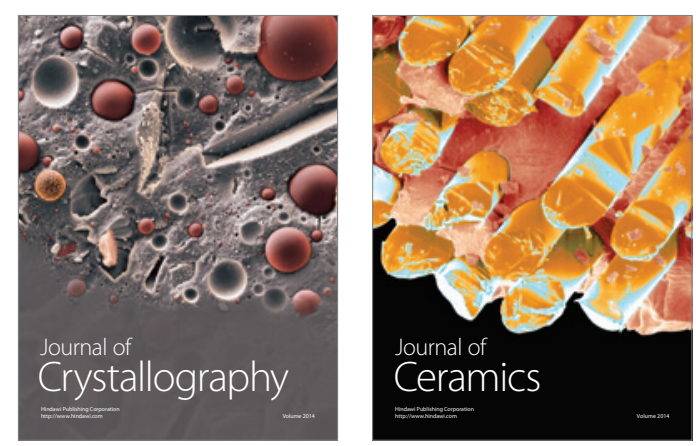
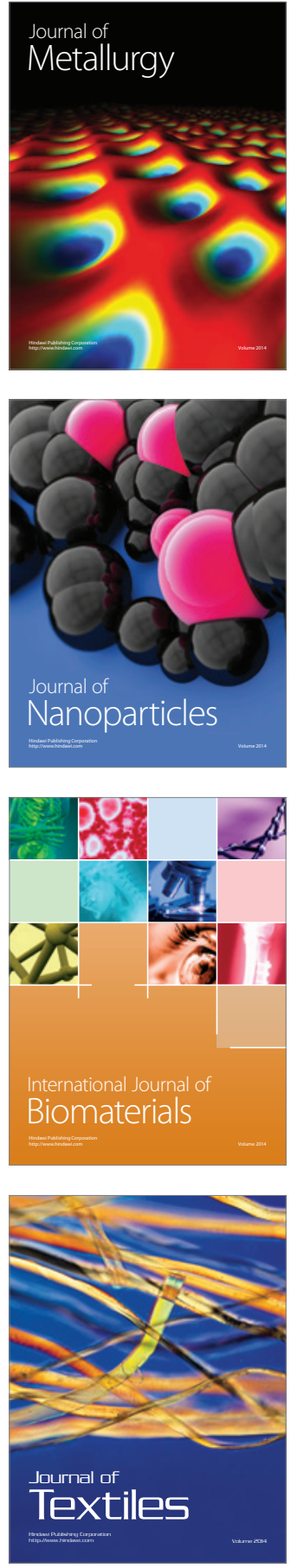